\title{
Intracameral cefuroxime in combined pars plana vitrectomy and phacoemulsification: a study of safety
}

This article was published in the following Dove Press journal:

Clinical Ophthalmology

\author{
Gianluca Besozzi' \\ Attilio Di Salvatore ${ }^{2}$ \\ Daniele Cardillo ${ }^{2}$ \\ Alessandro Finzi ${ }^{2}$ \\ Joseph Sajish Pinackatt ${ }^{2}$ \\ Andrea Baldi ${ }^{2}$ \\ Alessandro Monfardini ${ }^{2}$ \\ Valeria Forioli ${ }^{2}$ \\ Rino Frisina ${ }^{3}$ \\ Barbara Parolini \\ 'Department of Ophthalmology, \\ Vito Fazzi Hospital, Lecce, Italy; \\ ${ }^{2}$ Department of Ophthalmology, \\ Sant'Anna Clinical Institute, Brescia, \\ Italy; ${ }^{3}$ Department of Ophthalmology, \\ Padova University Hospital, \\ Padova, Italy
}

Background: Postoperative endophthalmitis is a severe complication after intraocular surgery. The aim of this pilot study was to investigate the safety of intracameral cefuroxime in combined vitrectomy and phacoemulsification for cataract and various vitreoretinal disease.

Methods: The charts of 152 patients who underwent combined phacoemulsification, intraocular lens implant and pars plana vitrectomy were reviewed. The final tamponade was chosen among fluid, air, gas or silicone oil, based on the requirement of each single case. Patients were operated on by four different surgeons. At the end of surgery, $1 \mathrm{mg} / 0.1 \mathrm{~mL}$ of intracameral cefuroxime (Aprokam) was administered.

Results: The mean follow-up was 6.26 \pm 7.78 months (range 1-12). No retinal complication, such as retinal infarction or hemorrhages were observed. No acute macular serous detachment and no new intraretinal cysts were noted, in those patients who received optical coherence tomography within the fifth day after surgery. No endophthalmitis was recorded.

Conclusion: Intracameral cefuroxime, at the end of combined phacoemulsification and pars plana vitrectomy, is safe as it has no toxicity on the retina and maybe could be considered effective in endophthalmitis prevention. Due to the relatively small number of patients, further studies are advisable.

Summary statement: The standard dose of intracameral cefuroxime at the end of combined phacoemulsification and pars plana vitrectomy has no toxic effects on the retina. This paper/The abstract of this paper was presented at the European Vitreo Retinal Society Conference 2017 as a conference talk with interim findings. The poster's abstract was not published.

Keywords: antibiotics retinal toxicity, cefuroxime, combined surgery, endophthalmitis prevention, intracameral cefuroxime, pars plana vitrectomy, phacoemulsification

\section{Introduction}

Postoperative endophthalmitis (POE) is a serious complication of intraocular surgery. It may lead to functional and even anatomical failure of the eye. POE could not be eradicated, but the incidence could be reduced by using povidone-iodine antisepsis preoperatively. ${ }^{1}$

In a large prospective randomized clinical trial, the European Society of Cataract and Refractive Surgery (ESCRS) demonstrated that the use of intracameral cefuroxime $1 \mathrm{mg} / 0.1 \mathrm{~mL}$, at the end of cataract phacoemulsification, reduces by 5 -fold the incidence of POE compared to topical antibiotics and no intracameral cefuroxime. ${ }^{2}$ Despite these exciting results, intracameral cefuroxime is not used everywhere in Europe and in US, mostly because of some concerns about costs and dilution errors that could lead to severe retinal complications, such as hemorrhagic retinal infarction. ${ }^{3}$ One case of
Correspondence: Gianluca Besozzi Department of Ophthalmology, Vito Fazzi Hospital, Piazza F. Muratore I, 73100 Lecce, Italy

Tel +393286I5 3808

Email gianlucabesozzi@gmail.com
Clinical Ophthalmology 2018:12 I567-1570

Dovepress if in 0

http://dx,doi.org/10.2/4710PTH.S17075। (c) (7) (5) 2018 Besozzi et al. This work is published and licensed by Dove Medical Press Limited. The full terms of this license are available at https://www.dovepress.com/terms.php cc) ${ }_{\mathrm{BY}} \mathrm{NC}$ and incorporate the Creative Commons Attribution - Non Commercial (unported, v3.0) License (http://creativecommons.org/licenses/by-nc/3.0/). By accessing the work you hereby accept the Terms. Non-commercial uses of the work are permitted without any further permission from Dove Medical Press Limited, provided the work is properly attributed. For permission for commercial use of this work, please see paragraphs 4.2 and 5 of our Terms (https://www.dovepress.com/terms.php). 
acute toxic serous macular detachment with cystoid macular edema was reported using intracameral cefuroxime and one after subconjunctival cefuroxime at correct concentration. ${ }^{4,5}$ Vitreoretinal surgery, as well, could lead to POE, and to our knowledge there are no reports about the use of intracameral cefuroxime in vitreoretinal surgery. The aim of this paper was to investigate the safety of the intracameral injection of cefuroxime $0.1 \mathrm{mg} / \mathrm{mL}$ at the end of combined cataract phacoemulsification and vitrectomy.

\section{Methods}

The charts of 152 consecutive patients were analyzed. Five minutes before surgery, periocular skin was disinfected with povidone-iodine $10 \%$, and drops of povidone-iodine $5 \%$ were instilled in the conjunctiva for 3 minutes. All the patients underwent uneventful cataract surgery and $23 \mathrm{~g}$ pars plana vitrectomy (23gPPV) for various vitreoretinal diseases by four different surgeons at Istituto Clinico Sant'Anna, GSD, Brescia, Italy. The final tamponade was chosen among fluid, air, gas or silicone oil, based on the requirement of each single case.

Intracameral cefuroxime (Aprokam, Laboratoires Thea) at concentration of $1 \mathrm{mg} / 0.1 \mathrm{~mL}$ was injected at the end of combined surgery through the clear cornea incision, after the tamponade injection and trocar removal.

Eyes were checked with a complete ophthalmological examination at postoperative day 1 and at postoperative day 7. Optical coherence tomography (OCT), fundus autofluorescence (FAF) and fluorescein angiography (FA) were performed if demanded by clinical features.

IRB of Sant'Anna Clinical Institute, Brescia, Italy, approved this study. Patient consent to review their medical records was not required by the IRB, and patients' data confidentiality were covered.

\section{Results}

The mean follow-up was 6.26 \pm 7.78 months (range 1-12). Combined surgery was performed by four surgeons: BP operated on 72 eyes, GB 40 on eyes, SP 32 on eyes and DC on eight eyes. The most common retinal pathology for combined surgery was epiretinal membrane (ERM), in 52 eyes. Thirty-six eyes underwent combined surgery for macular hole $(\mathrm{MH}), 20$ for regmathogenous retinal detachment, 16 for vitreous hemorrhage $(\mathrm{VH})$, eight for central retinal vein occlusion (CRVO) sequelae, four for recurrent RRD, six for metallic intraocular foreign body (IOFB), six for diabetic macular edema (DME) and four for vitreous floaters. After uneventful cataract phacoemulsification with intraocular lens implant in the bag, $23 \mathrm{gPPV}$ was performed to treat the vitreoretinal pathology. At the end of surgery, air was used as tamponade in 80 eyes, SF6 mixture ( $20 \%$ concentration) in 56 eyes, standard silicon oil (SSO) in eight eyes, heavy silicon oil (HSO) in four eyes and balanced salt solution (BSS) in four eyes. No endophthalmitis were reported. We found no evidence of retinal hemorrhages or retinal infarction during follow-up visits during ophthalmoscopic examination. Forty-eight eyes (32\%) received OCT examination within postoperative day, excluding signs of new acute serous macular detachment or new intraretinal fluid.

\section{Discussion}

Preventing endophthalmitis is a constant goal for every ophthalmic surgeon. The use of preoperative povidoneiodine antisepsis is proven to reduce significantly the rate of bacterial endophthalmitis. ${ }^{1}$ The role of preoperative topical antibiotics is still controversial. The ESCRS performed a large prospective randomized clinical trial and reported that the intracameral use of $1 \mathrm{mg} / 0.1 \mathrm{~mL}$ cefuroxime at the end of phacoemulsification reduced the incidence of postoperative endophthalmitis by approximately 5 -fold. ${ }^{2}$ However, POE is not an inconvenience that could occur only after cataract surgery, but also after every type of intraocular procedure. POE is reported even after pars plana vitrectomy with incidence that ranges from $0.018 \%$ to $1.53 \%$ in several series. ${ }^{6}$ The incidence of post vitrectomy endophthalmitis does not depend on the gauge used, and it could end with very poor visual acuity. ${ }^{6,7}$ Due to these data, prevention of post vitrectomy endophthalmitis was attempted by using subconjunctival antibiotics at the end of surgery. ${ }^{8}$ Two authors reported serious retinal complications after subconjunctival injection of gentamicin at the end of $25 \mathrm{gPPV}$ with sutureless sclerotomies. ${ }^{9,10}$ In both cases, the patient had a permanent severe visual loss due to macular infarction secondary to aminoglycoside toxicity. The authors speculate that the antibiotic might enter the eye through the unsutured sclerotomies, due to an early postoperative hypotony. One eye was tamponaded with an SF6 mixture, and this could lead to high antibiotic concentration that exacerbates the toxic effect, due to the non-dilution of the drug. ${ }^{10}$ The retinal toxicity of aminoglycoside has been well known for more than 20 years, especially in vitrectomized eyes. ${ }^{11-13}$ Beta-lactams antibiotics as well showed signs of retinal toxicity, since they have a posterior route of clearance from the eye. ${ }^{14}$ Intracameral cefuroxime caused retinal hemorrhage and infarction that resulted in very poor visual acuity in four patients in one published series, ${ }^{3}$ because of an inadvertent overdose of drug administered after uneventful cataract surgery. Two papers 
reported retinal toxicity from the use of a standard dose of cefuroxime, administered intracameral or subconjunctival, after uncomplicated cataract surgery. ${ }^{4,5}$ The authors described an acute macular detachment with intraretinal fluid which appeared at day 1-2 postoperatively and disappeared spontaneously at day 6-7. A toxic mechanism was speculated from the author who administered an intracameral standard dose of cefuroxime, because of the absence of leakage at FA and indocyanine green angiography (ICGA) that excluded the hematoretinal barriers disruption. Electroretinogram (ERG) was performed in one study and showed that the cefuroxime toxicity affected the entire retina. ${ }^{4}$ Recovery was spontaneous and fast, as the normal appearance of the macula was restored within 7 days. The intravitreal diffusion of an intracameral drug is determined by several factors: lens status, ${ }^{15}$ physicochemistry properties (molecular weight, ionic charge, liposolubility and solubility of the drug in his diluent), concentration gradient from the anterior chamber to the posterior segment, status of the vitreous (age, myopic refraction and surgical history) and on intraocular inflammation. ${ }^{16-18}$ The intravitreal diffusion and concentration of a drug are difficult to predict, especially in vitrectomized eyes and when the vitreous chamber is filled with gas or silicon oil. Both those agents lead to a higher concentration of the cefuroxime in the vitreous cavity, due to an absence of the possibility of dilution and to a compartmentalization of the drug. In our study, we found no evidence of retinal hemorrhage or infarction, which was the worst complication expected because of the higher concentration of cefuroxime in the vitreous chamber in those eyes tamponated with air, SF6 mixture and silicon oil. Many studies that assay intracameral cefuroxime safety in cataract surgery are based on OCT findings from week 4 to week 12 postoperatively, ${ }^{19,20}$ but we know that a very early toxicity could occur in the first postoperative days, with a spontaneous resolution with no sequelae within 7 days. We performed OCT in 48 eyes (32\%) within day 5 postoperative, and we found no evidence of new macular detachment or intraretinal, referable to already described cefuroxime toxicity. This is the first study, to our knowledge, that investigates the safety of a standard dose of intracameral cefuroxime at the end of combined phacoemulsification and small gauge pars plana vitrectomy. Our study has several limitations. The retrospective nature and the small number of patients do not allow us to comment on the efficacy of intracameral cefuroxime in preventing POE prevention. Also, we have to underline again that the purpose of the study was to investigate primarily the safety of intracameral cefuroxime in combined vitrectomy and phacoemulsification for cataract and various vitreoretinal disease, as there is no paper about this topic. Moreover, it could be a useful pilot study to exclude retinal cefuroxime toxicity which is the major concern in POE prevention, when combined surgery for cataract and various vitreoretinal disease is performed.

\section{Acknowledgment}

The authors have received no grants and/or funds in support of the study.

\section{Disclosure}

The authors report no conflicts of interest in this work.

\section{References}

1. Ciulla TA, Starr MB, Masket S. Bacterial endophthalmitis prophylaxis for cataract surgery: an evidence-based update. Ophthalmology. 2002;109(1):13-24.

2. Endophthalmitis Study Group, European Society of Cataract \& Refractive Surgeons. Prophylaxis of postoperative endophthalmitis following cataract surgery: results of the ESCRS multicenter study and identification of risk factors. J Cataract Refract Surg. 2007;33(6):978-988.

3. Çiftçi S, Çiftçi L, Dağ U. Hemorrhagic retinal infarction due to inadvertent overdose of cefuroxime in cases of complicated cataract surgery: retrospective case series. Am J Ophthalmol. 2014;157(2):421-425.

4. Faure C, Perreira D, Audo I. Retinal toxicity after intracameral use of a standard dose of cefuroxime during cataract surgery. Doc Ophthalmol. 2015;130(1):57-63.

5. Kontos A, Mitry D, Althauser S, Jain S. Acute serous macular detachment and cystoid macular edema after uncomplicated phacoemulsification using standard dose subconjunctival cefuroxime. Cutan Ocul Toxicol. 2014;33(3):233-234.

6. Czajka MP, Byhr E, Olivestedt G, Olofsson EM. Endophthalmitis after small-gauge vitrectomy: a retrospective case series from Sweden. Acta Ophthalmol. 2016;94(8):829-835.

7. Parolini B, Romanelli F, Prigione G, Pertile G. Incidence of endophthalmitis in a large series of 23-gauge and 20-gauge transconjunctival pars plana vitrectomy. Graefes Arch Clin Exp Ophthalmol. 2009;247(7): 895-898.

8. Recchia FM, Scott IU, Brown GC, Brown MM, Ho AC, Ip MS. Smallgauge pars plana vitrectomy: a report by the American Academy of Ophthalmology. Ophthalmology. 2010;117(9):1851-1857.

9. Cardascia N, Boscia F, Furino C, Sborgia L. Gentamicin-induced macular infarction in transconjunctival sutureless 25-gauge vitrectomy. Int Ophthalmol. 2008;28(5):383-385.

10. Brouzas D, Moschos MM, Koutsandrea C, Davou S, Georgalas I. Gentamicin-induced macular toxicity in 25-gauge sutureless vitrectomy. Cutan Ocul Toxicol. 2013;32(3):258-259.

11. Campochiaro PA, Lim JI. Aminoglycoside toxicity in the treatment of endophthalmitis. The Aminoglycoside Toxicity Study Group. Arch Ophthalmol. 1994;112(1):48-53.

12. Hancock HA, Guidry C, Read RW, Ready EL, Kraft TW. Acute aminoglycoside retinal toxicity in vivo and in vitro. Invest Ophthalmol Vis Sci. 2005;46(12):4804-4808.

13. Rosenbaum JD, Krumholz DM, Metz DM. Gentamicin retinal toxicity after cataract surgery in an eye that underwent vitrectomy. Ophthalmic Surg Laser. 1997;28:236-238.

14. Radhika M, Mithal K, Bawdekar A, et al. Pharmacokinetics of intravitreal antibiotics in endophthalmitis. J Ophthalmic Inflamm Infect. 2014;4(4):22.

15. Shaarawy A, Meredith TA, Kincaid M, et al. Intraocular injection of ceftazidime. Effects of inflammation and surgery. Retina. 1995;15(5): $433-438$. 
16. Kwok AK, Hui M, Pang CP, et al. An in vitro study of ceftazidime and vancomycin concentrations in various fluid media: implications for use in treating endophthalmitis. Invest Ophthalmol Vis Sci. 2002;43(4): 1182-1188.

17. Aguilar HE, Meredith TA, El-Massry A, et al. Vancomycin levels after intravitreal injection. Effects of inflammation and surgery. Retina. 1995; 15(5):428-432.

18. Koul S, Philipson A, Philipson BT, Arvidson S. Intraocular levels of cefuroxime in inflamed rabbit eyes. Eur J Ophthalmol. 1993;3(2): 61-65.
19. Lam PT, Young AL, Cheng LL, Tam PM, Lee VY. Randomized controlled trial on the safety of intracameral cephalosporins in cataract surgery. Clin Ophthalmol. 2010;4(4):1499-1504.

20. Gupta MS, Mckee HD, Saldaña M, Stewart OG. Macular thickness after cataract surgery with intracameral cefuroxime. J Cataract Refract Surg. 2005;31(6):1163-1166.

\section{Publish your work in this journal}

Clinical Ophthalmology is an international, peer-reviewed journal covering all subspecialties within ophthalmology. Key topics include: Optometry; Visual science; Pharmacology and drug therapy in eye diseases; Basic Sciences; Primary and Secondary eye care; Patient Safety and Quality of Care Improvements. This journal is indexed on

\section{Dovepress}

PubMed Central and CAS, and is the official journal of The Society of Clinical Ophthalmology (SCO). The manuscript management system is completely online and includes a very quick and fair peer-review system, which is all easy to use. Visit http://www.dovepress.com/ testimonials.php to read real quotes from published authors. 